\title{
Effective use of communication and information technology: bridging the skills gap
}

\author{
Allison H. Littlejohn and Lorraine A. J. Stefani \\ Centre for Academic Practice, University of Strathdyde, \\ email: allison.littlejohn@strath.ac.uk
}

There is a revolutionary culture change taking place within higher education in the United Kingdom. Part of this change is the adoption of new communication and information technologies (C\&IT), such as the World Wide Web (WWW), for teaching, learning and assessment. Many academics have limited experience of the WWW for teaching and learning and perceive that the use of new technologies involves transferring traditional teaching methods into an electronic format, with no regard for the underlying pedagogical implications. Our current research with teaching staff has given insight into essential skills and competencies required to empower the use of C\&IT bearing in mind the importance of the underlying pedagogy. In this paper we present an analysis of research carried out with academic staff members to determine the nature of staff and student skills needs regarding the use of C\&IT in teaching and learning. This analysis is followed by a case study of how these findings were incorporated into the development and implementation of a staff development programme aimed at encouraging innovative teaching at the University of Strathclyde.

\section{The importance of the effective use of C\&IT in teaching and learning}

In the context of academic induction courses, exploring conceptions of teaching and learning with new staff members confirms the notion that many academic staff want to teach as they have been taught. To encourage the adoption of new instructional strategies requires raising awareness of how students learn and supporting efforts to teach differently. Creative and flexible teaching requires an awareness of different methodologies, developing new skills with these methodologies and knowing when to apply these methods to optimize students' learning. The process of managing teaching for effective learning is further complicated when staff are expected to use new technologies. Some staff members show an added level of reluctance to engage in constructive dialogue about changes in frameworks for learning and teaching when the potential of communications and information technology (C\&IT) is discussed. 
An analysis of current literature supports the view that there is a limited conception amongst higher education teaching staff of how to use the WWW effectively for teaching and learning (Thomas, Carswell, Petre and Price, 1998). Their own undergraduate experience was likely to have been within a traditional university setting, so it may be difficult to conceive of a whole new framework. During our experience in facilitating staff development courses in using C\&IT for teaching and learning we have found that academics often view the WWW as another means by which they can 'deliver lecture notes', ignoring the importance of student dialogue. Current trends in higher education requiring increased student numbers are reducing the possibility of student-lecturer dialogue, which can in turn lead to students adopting a surface approach to learning (Mayes, 1995). This alarming trend may be exacerbated when using new methods of C\&IT because students and tutors have not discussed and agreed on a new teaching and learning framework and thus tutor and student responsibilities are unclear (Stefani and Nicol, 1997). The outcome for students is that course material may be unclear, difficult to navigate and non-engaging. This can be boring and demotivating, often further promoting surface learning. Students also need the opportunity to learn how to use available technologies responsibly and effectively in their learning, but all too often they are not given clear guidance on how to achieve this goal. Thus it is clear that C\&IT literacy skills for both staff and students must be incorporated into an overall strategy. The development of such strategies requires further research into the support needs for staff and students in higher education.

Research and development carried out with staff from across several higher education institutions has highlighted a number of perceived barriers to staff willingness to embrace C\&IT as a tool to enhance the teaching and learning environment (Stefani and Littlejohn, 1998; Littlejohn and Sclater, 1998). One of these perceived barriers can be articulated simply as the 'skills gap', which exists for both staff and students with respect to effective use of C\&IT. At a deeper level this particular barrier can be expressed in terms of many academic staff showing a lack of understanding of their pedagogical role in a C\&IT-based instructional environment. This interpretation is based on comments from many staff who display a reluctance to adopt teaching strategies that are different from those which they themselves experienced and a difficulty in acknowledging a theoretical underpinning of teaching and learning strategies.

The aim of this paper is to present a report of research carried out with academic staff members to determine the nature of staff and student skills needs regarding the use of C\&IT in teaching and learning. This analysis is followed by a description of how these findings were incorporated into a staff development programme aimed at encouraging innovative teaching at the University of Strathclyde.

\section{Exploring the skills gap: classroom research}

Staff perceptions of the learning skills required by students and the skills required by teachers were explored by asking two key questions:

1. What skills, competencies and attributes do students require so that they can learn actively and effectively in a technological environment?

2. What skills, competencies and attributes do tutors require in order to facilitate learning in a technological environment? 


\section{Staff perceptions of the required student learning skills}

Academic staff are expressing a growing concern over the 'skills gap' with respect to the effective use of C\&IT to enhance and enrich the teaching and learning environment. Research was carried out with academic staff from both the higher and further education sectors to determine the precise nature of this perceived skills deficit. This work was undertaken with academic staff members across several academic institutions and also in the context of workshops facilitated by the authors (for example Stefani and Littlejohn, 1998; Littlejohn and Cameron, 1998; Littlejohn and Sclater, 1998). Not surprisingly a varied picture emerges from the responses to the first key question, but it is possible to sift out a coherent list of the core skills and attributes which academic and related staff believe students require in order to learn effectively in a technological environment:

- basic study skills, e.g. reading, note-taking, ability to digest and analyse information;

- higher level study skills, e.g. thinking skills, critical reading and analysing skills;

- high-level problem-solving skills;

- an ability to formulate and articulate questions;

- motivation to learn;

- basic knowledge and understanding of IT skills such as filing, navigating and browsing skills;

- a concept of virtuality;

- an ability to work with others in a virtual environment and engage in asynchronous discussion;

- an open mind about the role of new technology in learning.

In addition to examining this list and its potential bearing on course and curriculum development it is worthwhile fully articulating some of the key comments made by academic staff in response to this question. One of the most interesting findings is the fact that more than half the skills articulated are required of students irrespective of their learning environment, whether real or virtual. This reinforces the point that the use of C\&IT cannot in itself transform teaching, learning and assessment. This will only be achieved by review and redevelopment of the curriculum and of the underlying pedagogies. The view that the success of using C\&IT for teaching and learning depends not so much on the technology as on the course and curriculum design has long been echoed by pioneers in the field of C\&IT (Reiser, 1994). Yet many staff development courses still aim to support the use of C\&IT in teaching and learning by focusing on technology rather than on pedagogical issues. Clearly a stronger emphasis on learning issues is required. Ehrmann (1995) makes the point that if you are headed in the wrong direction, technology will not get you to the right place.

Some staff believed that students require extrinsic motivation to use new technologies and that they require 'good learning experiences' to counteract their fears or phobias about new technologies. Student enthusiasm may depend on prior experience of technology. At times students are subjected to boring computer-aided learning packages by teachers who do not recognize that technology is only a tool which, when used properly, still requires 
that academic staff facilitate the student learning using this new tool. To interest students in technology there is perhaps a need for a more explicit articulation of the learning goals an important issue in conventional courses as well as online teaching and learning (Steinbach, 1997).

Our developmental work with staff indicated a positive sense that the use of online courses incorporating computer simulation scenarios which encompass information-gathering, information analysis and problem-solving enable students to develop higher-level cognitive skills such as critical thinking, anaiysing and problem-solving. Laurillard (1993) explored this issue in some depth in her book on Rethinking University Teaching. She supports this notion that higher-level skills can be cultivated within a virtual learning environment which adapts to the input provided by the student. The intrinsic feedback to the student provides a powerful learning experience, but only if the feedback pertains to the desired learning outcome. In other words, feedback which is poorly constructed will not lead to effective learning. Recently there has been an alarming trend in higher education leading to a reduction in feedback to students. In an article in The Times Higher Education Supplement, Terry Mayes (1997) suggested how this trend might be reversed in a reasonably efficient and effective way. Student feedback can take several forms: from dialogue between learner and teacher or peers to direct interaction with courseware. One of the most powerful features of new technologies is that they can render these dialogues 'reusable learning resources'. For example student-teacher dialogues can be recorded and set up as Frequently Asked Questions and so on (Mayes, 1997). This factor addresses one of the major conflicts expressed by staff. Such issues cannot be ignored if the use of technology is to be appropriately embedded into the student learning experience. What matters most is the effective development of educational strategies for using technology, which can influence the student's total course of study.

\section{Staff perceptions of the required skills for teachers}

Responses to the second key question reveal a fairly broad picture, but it is possible to distil a list of skills and attributes most commonly mentioned by academics in different settings:

- flexibility in approach to teaching and an openness to the use of new;

- technologies as another teaching tool;

- an understanding of learning styles and experiences;

- good communication skills;

- comfort with subject material;

- a willingness to learn from your students;

- a knowledge of your own limitations;

- a willingness to consider pedagogical issues associated with teaching and learning using new technologies;

- modelling the learning process through experimentation with new technologies and making the skills explicit;

- IT literacy skills; 
- an ability to face up to your fears of IT;

- knowledge of when to use what type of technology.

In addition to the list of core skills and attributes it is again worthwhile expanding on the dialogue between staff who participated in this project and the authors. One of the most interesting comments was that the increased emphasis on the use of new technologies in teaching and learning was in essence providing an opportunity for academic staff to rediscover pedagogy. This issue is strongly reflected in the fact that many of the key issues articulated pertain not only to the use of C\&IT, but also to conventional teaching and learning scenarios (for example Ramsden, 1992).

In pursuing this particular point staff commented that with the shift to a more C\&ITbased instructional environment lecturers/tutors should show a level of openness to the use of new technologies as another teaching technique, tool or method when appropriate. In other words one of the key skills for teachers may be expressed as knowing how to blend knowledge of the content of a course with higher-order pedagogical objectives using the methodologies and tools best suited to the learning context. Staff therefore require a level of awareness of different ways of managing teaching and learning. These findings highlight the importance of linking student learning outcomes with curriculum design and the selection of appropriate media (Conole and Oliver, 1998).

Within higher education there is an increasing expectation that learners be supported in developing transferable skills enabling them to mature as independent learners (Harvey, Moon and Geal, 1997). The qualities which are increasingly sought in the educated graduate do not include the ability to absorb and regurgitate a vast body of factual information, but rather the ability and skills associated with finding, evaluating and applying needed information (Breivik, 1997). These qualities combined with a desire to enable students to be autonomous self-directed learners (Cowan, 1988; Stefani, 1998) prepared for life-long learning allows an-essential list of skills which need to be embedded within the undergraduate curriculum. These skills include the ability to search for online resources, use online teaching materials, exchange ideas and engage in online dialogue, log on from home, retrieve course online information, publish assignments on the WWW and receive feedback online. A coherent curriculum focused on the student using C\&IT tools to manage students' learning has at its core the underlying principle of developing these essential skills. If these are not incorporated the outcome will be graduates who will be inclined to opt for resources that are easiest to access, irrespective of their validity and value. Sources such as books, journals, online databases and CD-ROMs are all learning tools which we must encourage students to use effectively as a matter of course. Therefore the increased emphasis on C\&IT may provide a platform for the development of a pedagogy for the new millennium.

\section{Supporting students in the use of C\&IT: reflections on pedagogy}

Reflecting on our classroom research tells us about underlying pedagogies and the need to ensure compatibility between the use of C\&IT and effective student learning. Our research into the skills gap associated with teaching and learning in a technological environment illustrates that university teachers have a good understanding of the barriers to effective use of new technologies in teaching and learning. But many of the responses to our two 
key questions are not specific to the use of new technologies but rather relate to teaching and learning in conventional settings. There is a contradiction in terms of the potential for C\&IT to transform teaching, learning and assessment of student performance and the actual adoption of new technologies. The use of C\&IT in teaching and learning has often been approached from a technological deterministic perspective which suggests that if C\&IT is used, teaching, learning and assessment will be automatically enhanced and improved due to the use of a technological medium (Thomas et al., 1998). While this concept fits well with the pressure on universities to make efficiency gains through the use of new technologies, it can in fact lead to misguided, erratic and unsuccessful attempts to use C\&IT. As Ehrmann eloquently states, we may not be asking the right questions to facilitate effective answers (Ehrmann, 1995).

In light of the inexorable drive to increase the level of C\&IT usage in teaching and learning, academics should consider the present time to be a period during which our notions of course and curriculum design can be fully reviewed. While there has been much emphasis over the past decade on ensuring that transferable skills are an explicit component of any discipline-based curriculum, the focus has tended to be on communication, presentation, numeracy, problem-solving and self-assessment skills (Anderson and Marshall, 1996). To enable the development of these higher-level skills using C\&IT it could be argued that supporting students in developing information literacy skills is now an essential element of the curriculum. Many UK universities are addressing this issue by introducing information skills literacy training programmes which are increasingly becoming a requirement for graduation (Martin, 1997). However, programmes focusing solely on the development of IT skills ignore additional learning and information management skills. Increasingly students will be required to make a cognitive transformation from more traditional methods of learning to active learning managed around a personal computer. It is, therefore, essential that these skills are embedded into student support programmes in order to link the effective use of C\&IT with pedagogical principles (Breivik, 1997).

\section{Bridging the skills gap: staff development programme}

Our exploration of the 'skills gap' has enabled us to focus more effectively on the key issues in supporting academics in making effective use of the WWW for teaching and learning. The Strathclyde Learning Technology Initiative included a staff development programme aiming to facilitate strategic change in the development and use of new technologies in teaching and learning at the University of Strathclyde. Our research into exploring the 'skills gap' enabled us to take into consideration the anxieties and barriers to the use of new technologies expressed by academics.

\section{Programme structure}

A coherent programme was developed incorporating five short staff development courses including:

1. Choosing the right technology.

2. Web-based teaching.

3. Electronic assessment. 
4. Internet communication.

5. Electronic libraries.

These courses were designed around the premise that the technologies employed serve only as a tool. The main emphasis is on the development of a strong pedagogical basis. Academics can easily develop the technical skills necessary to build an educational website. However, our research has highlighted the recognition by academics that without grounding in sound pedagogical practice these sites can be sterile and uninspiring learning environments.

\section{Programme delivery}

Academics are familiar with teaching in traditional settings, but how did we face the challenge of enabling them to make the cognitive link between teaching in 'real' compared with 'virtual' environments? The use of a Virtual University model provided a conceptual framework, enabling staff to compare the similarities and differences of a virtual learning environment with a conventional university campus. The Clyde Virtual University (CVU, http://cvu.strath.ac.uk) is a virtual learning environment integrating the main components of a traditional university: lecture theatre, library, assessment hall, virtual café and administration office. This model provided an excellent conceptual framework for academics new to web-based teaching. It illustrates how all the components can be integrated even more easily than by traditional means, creating a powerful integrated learning environment. It also has an easy-to-use assessment engine and text-based chat facilities, providing a platform for easy development of teaching materials. The aim is to render the technology as transparent as possible, freeing academics to concentrate on their teaching and learning (Littlejohn and Sclater, 1998).

All courses involve the participation of between eight and twelve members of staff in a full day session. As far as possible staff members are placed in the role of students, for example when reviewing existing teaching materials, or while using new technologies to exchange ideas enabling academics to reflect ùpon how their students would fare in a virtual teaching environment.

Choosing the right technology

This course provides a brief overview of how technologies are currently used to enhance teaching and learning. Key issues articulated during our research are highlighted; including the selection of appropriate media and integration of a C\&IT-based course into mainstream teaching. Internet communication tools, such as shared whiteboards and bulletin board discussions are demonstrated.

Web-based teaching

Our research highlighted the development of an effective pedagogical strategy as an essential skill for academics. Therefore this skill is the main focus of the course on webbased teaching. Case studies are presented and discussed, before participants are given the opportunity to critique an educational website within their own field. Afterwards a 'handson' session is devoted to storyboarding and learning the practical skills required to create a short course. These practical skills can be further developed in additional online courses.

Electronic assessment

Since learning goals are often driven by the assessment it is essential to ensure that an appropriate form of assessment is developed. Electronic assessment methods are still 
somewhat limited, but can be highly appropriate and useful if incorporated coherently into web-based courses, where an overall assessment strategy will include summative and formative assessment and peer, self and tutor assessment. These issues are highlighted during the workshop on electronic assessment. Examples of different electronic assessment techniques are compared and discussed, providing a powerful insight into the effectiveness of various forms of electronic assessment. The afternoon session enables lecturers to develop and create their own simple Electronic Assessment using the Clyde Virtual University Test Wizard. This tool enables staff to create web-based assessments without the requirement of technical sixills. By following a few simple steps web-based assessments can be created in a matter of minutes, rendering the technology almost transparent, thereby enabling academics to focus their attention on writing assessment questions which reflect the learning goals.

\section{Internet communication}

The importance of student dialogue via communication technologies was acknowledged by academics as a key component in the design of an effective course. This point is emphasized during the workshop on internet communication, which is run in collaboration with the Glasgow Caledonian University. Participants discuss and debate the importance of dialogue using communication tools such as desktop videoconferencing, audio chat, text conferencing, shared whiteboards and collaborative browsing. Ideas focused on case studies are exchanged throughout the day and the session culminates in an inter-university debate using ATM videoconferencing.

\section{Electronic libraries}

The course on electronic libraries enables academics to develop the information management and retrieval skills which they articulated as essential. The course explores library and information services available over the WWW, including worldwide access to electronic journals, library catalogues and databases, email-based library reference services, document delivery services and Internet search tools.

\section{Developing teaching and learning strategies in a technological environment}

The staff development programme described in this paper shows how research and development work with staff to determine the specific nature of the skills deficit has been used to develop a participant-friendly staff development programme. The goal was to encourage an emphasis on key issues such as curriculum redevelopment, promoting dialogue, the role of electronic assessment and the integration of technology-based courses into mainstream teaching and learning.

The effectiveness of this programme will ultimately be measured by two factors: the numbers of participants on this programme who subsequently use C\&IT in their teaching and learning and the quality of the courses they develop. Presently about half the programme participants are actively involved in developing innovative teaching methods in their subject discipline. For example the Department of Forensic Science is developing an online assessment of a virtual crime scene. Students are presented with an online crime scene and have a number of options for sample collection and analysis. The order in which data are collected will ultimately affect the nature and quality of the results. Therefore 
students are required to analyse the information given and develop a strategy for sample collection to attain successful results. The underlying pedagogical outcome is that students will be better versed in how to proceed with analysis when faced with a real crime scene.

It is generally accepted now that these skills enhancement opportunities should be embedded within the curriculum rather than bolted on as optional extras. Creating opportunities for students to develop higher-order learning skills and to develop the information literacy skills essential to life-long learning may require more sophisticated changes to course and curriculum development. However, it can still be argued that university institutional structures do not encourage efforts to change and improve teaching (Albright and Graff, 1992). Primarily there appears to be a lack of vision of technology as an integral part of the curriculum, resulting in C\&IT activities being bolted on to the curriculum rather than thoughtfully included in ways which fully consider pedagogical parameters. Inevitably this trend has led to the perpetuation of traditional teaching systems through technology rather than to innovations in teaching and learning styles and methods.

University lecturers must take the main responsibility not only of what, but also for how our students learn. With some careful consideration and a willingness on the part of university lecturers to change, computer-based technologies can be used to create an environment where students are helped to think constructively, critically and reflectively. If we are serious in our goal of enabling students to become independent learners and innovative critical thinkers it is essential to create a more student-centred curriculum and utilize teaching methods which encourage student participation, reflection and feedback. We need to be more willing to create a learning culture in which the students themselves are actively engaged in the creation of knowledge which they share with their peers and their lecturers who in turn give feedback and critique to stimulate further thinking, exploring and learning. The lecturer in this scenario is no longer the centre of authority, rather s/he is a facilitator of active learning and plays an important role in providing feedback, cues for further enquiry and support for the development of a learning community. Achieving those pedagogical aims requires several action points to be considered including more problem-based learning within the curriculum; developing new partnerships across faculty and the university campus; and urging a more coherent institutional response regarding the technology-based infrastructure of the university campus.

All of the above must be within the context of a supporting environment. For example, there must be adequate provision for students and staff to access the virtual learning environment. This is a difficult issue for the University, since it is expensive and resource-intensive. Finance must be targeted effectively. Staff development courses provide a mechanism for discussion and channelling of ideas and requirements to the appropriate IT committees. It is also important to create a 'community of scholars' wishing to use C\&IT to such an extent that eventually there will come a point where a critical mass of university teachers have the skills to develop courses utilizing communication and information technology.

\section{Acknowledgements}

The authors would like to thank Niall Sclater and Shona Cameron of the Centre for Educational Systems for their contributions towards the staff development programme at the University of Strathclyde. 


\section{References}

Albright, M. J. and Graff, D. L. (eds.) (1992), 'Teaching in the information age: the role of electronic technology', New Directions for Teaching and Learning Series No. 51, San Francisco: Jossey Bass.

Anderson, A. and Marshall, V. (1996), 'Core versus occupation specific skills', DFEE Research Brief, Research Studies RS12, 32, HMSO Books, 24 July 1996.

Breivik, P. S. (1997), Student Learning in the Information Age, American Council on Education, Phoenix, Arizona: Oryx Press.

Cowan, J. (1988), 'Struggling with self-assessment', in Boud, D. (ed.), Developing Student Autonomy in Learning, Kogan Page: London, 192-210.

Conole, G. and Oliver, M. (1998), 'A pedagogical framework for embedding C\&IT into the curriculum', ALT-J, 6 (2), 4-16.

Ehrmann, S. C. (1995), 'Asking the right question: what does research tell us about technology and higher learning', Change Magazine: The Magazine of Higher Learning, 27, 2 (March/April 1995), 20-7.

Harvey, L., Moon, S. and Geal, V. (1997), Graduate's Work: Organizational Change and Student's Attributes; Centre for Research into Quality and the Association of Graduate Recruiters, University of Central England, Birmingham.

Laurillard, D. (1993), Rethinking University Teaching: A Framework for the Effective Use of Educational Technology, London: Routledge.

Littlejohn, A. H. and Cameron, S. (1998), 'Supporting strategic cultural change', paper presented at ALT-C 98, University of Oxford, UK.

Littlejohn, A. H. and Sclater, N. (1998), 'Overcoming conceptual barriers to the use of internet technology in university education', Proceedings of WebNet Conference, Association for the Advancement of Computing in Education, Orlando, FL, USA, 586-91.

Littlejohn, A. H. and Stefani, A. J. (1998), 'Exploring the gap between the concept and the reality of using new technologies in teaching and learning', paper presented at the Staff and Educational Development Association Conference, University of Southampton, UK.

Martin, A. (1997), 'Student IT introduction: an evolving requirement', Active Learning, 6, 41-7.

Mayes, J. T. (1995), 'Learning technology and groundhog day hypermedia at work: practice and theory in higher education', in Strang, W., Simpson, V. and Slater, D. (eds.) Canterbury: University of Kent Press, 21-37.

Mayes, J. T. (1997), 'Dialogue with a dumb terminal', The Times Higher Education Supplement, Multimedia ix, 10 October 1997.

Ramsden, P. (1992), Learning to Teach in Higher Education, London: Routledge.

Reiser, R. A. (1994), 'Clark's invitation to the dance: an instructional designer's response', Educational Technology Research and Development, 42 (2), 45-8. 
Stefani, L. A. J. (1998), 'Assessment in partnership with learners', Assessment and Evaluation in Higher Education, 23 (4), 339-50.

Stefani, L. A. J. and Nicol, D. J. (1997), 'From teacher to facilitator of collaborative enquiry in facing up to radical changes in universities and colleges', in Armstrong, $S$., Thompson, G., and Brown, S. (eds.), Facing Up to Radical Changes in Universities and Colleges, Kogan Page: London, 131-40.

Steinbach, P. (1997), 'Classroom applications of technology attract some students, alienate others', Quality in the Classroom - a quarterly supplement to Quality in Higher Education, 7, 1-4, Madison, WI: Magna Publications.

Thomas, P. J., Carswell, L., Petre, M., Price, B. A. (1998), 'A holistic approach to supporting distance learning using the internet: transformation, not translation', British Journal of Educational Technology, 29 (2), 149-61. 